\title{
BMJ Open Age, occupational class and sickness absence during pregnancy: a retrospective analysis study of the Norwegian population registry
}

\author{
Anja M S Ariansen
}

To cite: Ariansen AMS. Age, occupational class and sickness absence during pregnancy: a retrospective analysis study

of the Norwegian population registry. BMJ Open 2014;4: e004381. doi:10.1136/ bmjopen-2013-004381

- Prepublication history for this paper is available online. To view these files please visit the journal online (http://dx.doi.org/10.1136/ bmjopen-2013-004381).

Received 5 November 2013 Revised 13 March 2014 Accepted 10 April 2014

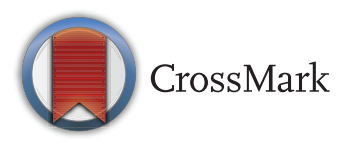

Department of Sociology, University of Bergen, Bergen, Norway

Correspondence to Anja M S Ariansen; anja.steinsland@sos.uib.no

\section{ABSTRACT}

Objective: Western women increasingly delay having children to advance their career, and pregnancy is considered to be riskier among older women. In Norway, this development surprisingly coincides with increased sickness absence among young pregnant women, rather than their older counterparts. This paper tests the hypothesis that young pregnant women have a higher number of sick days because this age group includes a higher proportion of working class women, who are more prone to sickness absence.

Design: A zero-inflated Poisson regression was conducted on the Norwegian population registry. Participants: All pregnant employees giving birth in 2004-2008 were included in the study. A total number of 216541 pregnancies were observed among 180483 women.

Outcome measure: Number of sick days.

Results: Although the association between age and number of sick days was $\mathrm{U}$-shaped, pregnant women in their early 20s had a higher number of sick days than those in their mid-40s. This was particularly the case for pregnant women with previous births. In this group, 20-year-olds had 12.6 more sick days than 45-year-olds; this age difference was reduced to 6.3 after control for class. Among women undergoing their first pregnancy, 20-year-olds initially had 1.2 more sick days than 45-year-olds, but control for class altered this age difference. After control for class, 45 -year-old first-time pregnant women had 2.9 more sick days than 20-year-olds with corresponding characteristics.

Conclusions: The negative association between age and sickness absence was partly due to younger age groups including more working class women, who were more prone to sickness absence. Young pregnant women's needs for job adjustments should not be underestimated.

\section{OBJECTIVE}

Western women increasingly delay having children to advance their career, ${ }^{1}$ and pregnancy is normally regarded as being riskier among older women. ${ }^{2}$ In Norway, this

\section{Strengths and limitations of this study}

- Retrospective analyses of a population registry reveal that heightened sickness absence among young pregnant women in Norway is partly due to a preponderance of working class women in this age group.

- The data employed include information about all employees giving birth in 2004-2008; thus, the risks of type I and II errors are eliminated.

- The data consist of official recordings, which make sure that the estimates do not suffer from bias due to self-reporting or non-response.

- Because some absence spells are left censored, zero-inflated Poisson regression has been conducted.

- Although occupational class has a major impact on sickness absence among pregnant women in this study, the data do not allow for assessing the relative contribution of working conditions.

- Age differentials among pregnant women with previous deliveries remain largely unexplained.

development coincides with increased sickness absence during pregnancy. Somewhat surprisingly, the increased sickness absence primarily applies to young pregnant women rather than their older counterparts. ${ }^{34}$

Previous research has revealed that sickness absence during pregnancy is influenced by the pregnant women's workplace, through adjustments and social interaction with colleagues. ${ }^{5} 6$ This paper broadens the scope of this literature by emphasising how the women's workplace is also influenced by recent shifts in fertility and employment patterns. Age during pregnancy has become increasingly linked to socioeconomic factors such as education and occupation. ${ }^{1}$ The aim of this paper is to examine whether the heightened sickness absence among young pregnant women in Norway is due to a preponderance of working class women in this group. 


\section{BACKGROUND AND SIGNIFICANCE}

Because the Norwegian sickness benefit is very generous, growing levels of sickness absence have created concerns about future public costs. ${ }^{7}$ In this context, more frequent sickness absence among young pregnant women may easily be seen as a reflection of unsustainable welfare consumption in younger generations. Such speculation is problematic, because pregnant women may respond to others' negative views on them with risky behaviour. ${ }^{8}$

The need to investigate sickness absence during pregnancy is further enhanced by studies suggesting that employers' or colleagues' negative expectations of the work performance or sickness absence of pregnant employees may challenge these women's career opportunities, ${ }^{5}{ }^{9-12}$ even when the empirical basis for these assumptions is lacking. ${ }^{13-15}$ These issues highlight the importance of ensuring that heightened sickness absence among young pregnant women is addressed through empirical investigation and evidence-based policies rather than unsound generalisations and discrimination.

Sickness absence during pregnancy has increased substantially over the past two decades in Norway, and the relative increase and total level of sickness absence is highest among younger women. ${ }^{3}{ }^{4} 16$ However, the impact of the occupational class on this age difference is unknown. Previous research on sickness absence during pregnancy has rarely focused on the impact of pregnant women's age and their class affiliation, except from three studies of Swedish data from the 1980s, which reached different conclusions. The first study concluded that sickness absence during pregnancy in Sweden in the late 1980s was characterised by class differentials, but only marginal age differentials. ${ }^{17}$ However, the other two studies highlighted that a preceding increase in sickness absence during pregnancy applied particularly to young women, ${ }^{18}$ and that young age during pregnancy was associated with a higher frequency of sickness absence. ${ }^{19}$ These findings indicate that high and increasing levels of sickness absence among young pregnant women do not constitute a strictly Norwegian phenomenon.

Although the tight link between pregnant women's age and their class position has not received much attention in previous research on sickness absence, the issue has been highlighted in demographic research. 'The second demographic transition' refers to growing female employment, postponement of pregnancy and decreasing birth rates which have occurred in western countries. $^{20}$ However, these trends primarily characterise women with higher education and privileged class positions. ${ }^{21}{ }^{22}$ In Norway, a postponed first birth is often followed by a shorter duration between the first and second births. ${ }^{23}$ This leads to the expectation that class differentials in the timing of pregnancy are larger in the group of first-time pregnant women than among those with previous births.

As increased sickness absence among young pregnant women in Norway coincides with growing class differentials in timing of pregnancy, it seems relevant to question whether age differentials in sickness absence during pregnancy may be confounded by class. This concern is substantiated by a wide range of studies which emphasise the impact of occupational characteristics on pregnant women's health problems or sickness absence. Shift work and physical strain in terms of lifting or standing is associated with preterm birth. ${ }^{24}{ }^{25}$ Heavy lifting, as well as exposure to certain chemicals, increases the risk for miscarriage and decreases birth weight. ${ }^{26-28}$ Physical strain increases sickness absence, ${ }^{29}{ }^{30}$ while the opportunity for job adjustments reduces sickness absence. ${ }^{6}{ }^{31}$ Moreover, pregnant employees express that they strive to meet those standards of bodily control and appearance that are expected at their workplace. ${ }^{5} 32$ These accounts highlight the need for adjustments, such as breaks and permission to work from home, which are more common in higher ranking occupations. ${ }^{33}$ Class is also related to sickness absence and pregnancy through norms and values. Sickness absence may be regarded as more legitimate in a 'working class culture'. ${ }^{34}$ Working class occupations are also more gender segregated, ${ }^{35}$ and female-dominated workplaces have somewhat higher levels of sickness absence in Norway, possibly because of gender-specific norms. ${ }^{36}$ Working-class women are more likely to express family-oriented values, while middle-class women more often are characterised by occupational dedication. ${ }^{37}$ However, housewives tend to have more health problems than employed women. ${ }^{38}$ To the extent that early pregnancy indicates future housewifery, this could thus be a choice born of necessity rather than a preference for women with health problems.

To summarise, women's age at first pregnancy varies according to occupational class, and occupational class may influence sickness absence during pregnancy in several ways. This leads to the following hypotheses:

H1: The negative association between age and sickness absence among pregnant women is more pronounced among pregnant women undergoing their first pregnancies than among pregnant women who have previously given birth.

H2: The negative association between age and sickness absence levels out when occupational class is controlled for among first-time pregnant women and those who have previously given birth.

\section{MATERIALS AND METHODS}

The following analyses are based on data collected by the Norwegian Labour and Welfare Administration, the Norwegian Tax Administration and the Ministry of Health and Care Services. The national agency Statistics Norway of the Ministry of Finance has adapted the data for research. The collected data include information about each individual of the entire Norwegian population. Use of population data from public records ensures that our estimates are not biased 
by non-response or self-reporting. Furthermore, the risk of type I or type II errors is eliminated because the analyses are based on data from the population rather than from a random sample.

The data contain all women in the Norwegian population giving birth during the years 2004-2008. After deleting 2537 deliveries with unknown mothers, a total number of 286104 deliveries were registered during the observed period. Further, 30 registered deliveries were excluded due to a missing value on the variable Age. Because the aim of the paper is to address the occupational challenges among young pregnant women rather than the particular difficulties associated with teenage pregnancies, 1473 teenage pregnancies were excluded from the analyses. Subsequently, the age span of the study population varied from 20 to 54, although less than $2 \%$ of the women were older than 40 in the year of delivery. Finally, 168 women were excluded due to lack of registration of the woman's marital status.

Of the remaining pregnancies, a total number of 216541 met the inclusion criteria that the pregnant woman had registered earnings in the year of delivery, and had worked at least $1 \mathrm{~h}$ /week on average during the employed period of pregnancy. Of these, $16286 \mathrm{had}$ missing values on the variable Occupational class. A separate dummy variable for these observations was added to the set of dummy variables which the occupational class consists of. About $0.6 \%$ of the registered sickness absence spells were excluded from the analyses due to missing values on the variable Compensated sick days. As some women underwent more than one of the registered pregnancies, a total number of 180483 individuals are included in the analyses. Pregnancies that apply to the same woman are treated as different observations in the analysis; thus, the total number of observations is 216541.

The generous sickness benefit provisions in Norway ensure that most employees listed as sick receive full-wage compensation for an entire calendar year. The payout has an upper limit which in 2008 amounted to NOK414 648, or about $€ 52799$. Separate rules for sickness absence apply to the self-employed, which makes comparison with employees difficult. For this reason, self-employed women were excluded from our analyses.

The registry only provides consistent recording of all spells of sickness absence from the 17th calendar day, while recording of spells prior to this day depends on the woman's diagnosis and her employer's request for reimbursement. Each woman's value of the dependent variable Sick days equals the total number of sick days for which she received the National Insurance sickness benefit in the 282 days preceding birth. The variable also includes spells of absence covered by the pregnancy benefit, which are certified by physicians if they consider the pregnant woman's tasks or working environment to threaten the fetus. In order to prevent registration errors from turning into influential outliers, the variable Sick days was limited to an upper value of 192. This number amounts to $68 \%$ of the total number of calendar days of the total pregnancy period of 282 days, and is equivalent to the maximum percentage of calendar days compensated by the National Insurance for nonpregnant employees during 1 year.

A pregnancy period of 282 days is equal to the expected gestational age, which is counted from the first day of the last menstrual period prior to conception, and extends the period from conception to birth by 14 days. Norwegian health professionals frequently refer to gestational age as a measure of pregnancy duration when consulting women who are or plan to become pregnant, possibly increasing their awareness of symptoms even prior to conception. Because this awareness may influence sickness absence behaviour, the categorisation of sickness absence during pregnancy was based on expected gestational age.

The occupational codes in the registry data were grouped according to the class scheme of Erikson, Goldthorpe and Portocarero (EGP), ${ }^{39}$ by means of a detailed manual provided by Flemmen. ${ }^{40}$ Utilisation of the EGP class scheme ensures international comparability, ${ }^{41} 42$ and the class scheme has shown a consistent association with health inequality, ${ }^{43}$ which makes it suitable when investigating sickness absence. As mentioned earlier, selfemployed women were excluded from the study population, and accordingly the class of self-employed was omitted from the analyses.

The variable Previous deliveries indicates whether a woman is registered as having given birth since 1 January 1992. The variable Age equals the age of the pregnant woman in the year of delivery. The variable Age squared was added to account for the possibility of a curved association between age and sickness absence.

Previous research indicates that the association between pregnant women's age and their occupation may be more pronounced during first pregnancy than subsequent ones. ${ }^{45}$ The product of the variables Age and Previous deliveries is included in the regression analyses to account for such interactions.

All estimates are adjusted for possible confounders in terms of calendar year, weekly working hours, timing of transition to parental leave and marital status, but for simplicity these control variables were left out of the analysis.

Thus, the following variables are included in the Results section:

- Sick days: Continuous dependent variable, the natural logarithm of the pregnant woman's number of sick days covered by the National Insurance scheme.

- Age. Continuous independent variable. The age of the pregnant woman.

- Age squared: Continuous independent variable. The squared age of the pregnant woman.

- Occupational class: Dummy set of independent variables. Reference group: I Higher professionals. Other categories: II Lower professionals, III a Higher routine, IIIb Lower routine, V Technicians, VI Skilled, VII Semiskilled and unskilled, VIIb Agricultural, Missing. 
- Previous deliveries: Independent dummy variable. Women with previous deliveries take the value of 1. Women who undergo their first pregnancy take the value of 0 .

- AgexPrevious deliveries: Independent interaction variable equalling the value of Age multiplied by the value of Previous deliveries.

- Year. Dummy set of control variables. Reference group: Women giving birth in 2004. Other categories: Year 2005, Year 2006, Year 2007, Year 2008.

- Working hours: Continuous control variable. Average number of hours of paid work per week.

- Leave: Continuous control variable. Total number of days between pregnancy onset and either transition to parental leave or date of delivery.

- Marital status: Dummy set of independent variables. Reference group: Unmarried. Other categories: Married, Divorced, Widowed.

\section{METHODS}

The dependent variable in the following analyses can be characterised as count data, because it represents the total number of sick days and thus only contains positive integer values. The large proportion of women with the value of 0 on this variable indicates that the distribution may be characterised by an inflated zero, which means that the value of the variable and the likelihood of this value being 0 is influenced by external factors. ${ }^{46}$ For example, the value of 0 sick days can be influenced by working hours in two different ways. Because part-time employees have a lower maximum number of sick days than do full-time employees, a larger proportion of parttimers probably have no actual sick days. However, they are probably also more likely to have shorter spells, which in turn are more likely to be left censored, and take the value of 0 for this reason. This also applies to women with early transition to maternity leave. To account for the excess of zero sick days among women with few working hours and/or early transition to maternity leave, a zero-inflated Poisson regression model was conducted. This choice of model was supported by a significant Vuong test, which indicates that the zip model fits the data better than the standard Poisson model.

The zip model consists of two components, because the predicted value of Sick days is combined with a prediction of the probability of achieving a value of 0 . In the count component, each regression coefficient reveals changes in the log of the expected value of the number of sick days produced by a one-unit increase in a given variable when other independent variables are held constant. Because the substantial meaning of the coefficients is not readily apparent, marginal plots will be provided for the core findings.

In an excess zero component, the variables Working hours and Leave are used as predictors of values exceeding zero in all four regression models. This indicates that the inflation of 0 sick days is partly due to the inclusion of employees with few contracted working hours and/or early transition to parental leave, which reduces the possible number of sick days. In analyses of samples drawn from a population, the purpose of significance testing regression coefficients is to assess the likelihood that the estimates that apply to the sample also apply to the population as a whole. For analyses based on a population rather than a sample drawn from it, this condition is already satisfied. For this reason, significance testing is left out of the following regression models.

\section{RESULTS}

Descriptive statistics of the study population are listed in table 1, and confirm that higher and lower professionals are characterised by fewer sick days, higher age and a higher number of working hours than skilled and unskilled workers.

The distribution of Sick days is characterised by an inflated zero (figure 1). Investigation of the association between age and sickness absence among full-time employees indicates that the association is curved rather than linear (figure 2).

Table 2 shows a zero-inflated Poisson regression, which includes two components. The Count component is a prediction of Sick days, and models 1-4 show the varying associations that follow from different sets of independent variables. The Excess zero component predicts the probability of taking no sick days after control for Working hours and Leave, and remains unchanged in all four models. The count component of model 1 shows the unadjusted association between Age and Sick days, while models $2-4$ are adjusted for confounders.

Model 1 reveals a positive coefficient for Age squared, which confirms the U-shaped association between age and sickness absence revealed in figure 2. The coefficient is still positive after control for Year, Working hours, Leave and Marital status in model 2.

In model 3, the variable Previous deliveries and the product of Age and Previous deliveries are included to investigate whether the associations between age and sickness absence differ between women with and without previous births. Since the interpretation of the interaction coefficients is complicated, the interaction effect is illustrated in figure 3 .

The values of the coefficients change by control for occupational class in model 4 . The implications of this change are also illustrated in figure 3. All the occupational classes have positive coefficients, indicating that each class has a higher number of sick days than the baseline category, which is I Higher professionals.

Cragg and Uhler's ${ }^{47}$ R2, also referred to as Nagelkerke's R2, is a measure of model fit that varies between 0 and 1 . High values indicate a better prediction of counts in the current model than in the intercept model, which equals a model without independent variables. In model 1, the value of Cragg and Uhler's R2 
Table 1 Descriptive statistics of the study population (according to occupational class)

\begin{tabular}{|c|c|c|c|c|c|c|c|c|c|c|}
\hline & \multicolumn{2}{|c|}{ Sick days } & \multicolumn{2}{|l|}{ Age } & \multicolumn{2}{|c|}{$\begin{array}{l}\text { Working } \\
\text { hours }\end{array}$} & \multicolumn{2}{|l|}{ Leave } & \multirow{2}{*}{$\begin{array}{l}\text { Married } \\
\text { Per cent }\end{array}$} & \multirow{2}{*}{$\begin{array}{l}\text { Previous } \\
\text { deliveries } \\
\text { Per cent }\end{array}$} \\
\hline & Mean & SD & Mean & SD & Mean & SD & Mean & SD & & \\
\hline I Higher professionals & 34.2 & 43.5 & 33.3 & 3.9 & 34.3 & 7.6 & 263.2 & 10.3 & 55.8 & 55.5 \\
\hline II Lower professionals & 39.8 & 45.5 & 32.5 & 3.9 & 33.8 & 7.6 & 263.2 & 10.2 & 50.7 & 53.6 \\
\hline Illa Higher routine & 50.4 & 48.8 & 30.1 & 4.6 & 29.0 & 10.4 & 264.1 & 10.8 & 42.8 & 55.0 \\
\hline Illb Lower routine & 54.6 & 50.0 & 29.0 & 5.0 & 25.9 & 11.6 & 264.8 & 11.1 & 35.5 & 53.0 \\
\hline V Technicians & 43.8 & 47.7 & 32.1 & 4.4 & 33.0 & 8.0 & 264.5 & 10.8 & 41.6 & 60.5 \\
\hline VI Skilled & 51.4 & 49.6 & 28.8 & 4.9 & 29.1 & 10.6 & 263.8 & 10.7 & 32.9 & 52.0 \\
\hline VII Semiskilled and unskilled & 51.9 & 52.1 & 29.1 & 5.2 & 22.7 & 12.8 & 266.4 & 12.3 & 41.7 & 51.2 \\
\hline VIIb Agricultural & 37.6 & 47.0 & 28.3 & 4.9 & 24.9 & 12.9 & 265.9 & 12.0 & 35.2 & 51.1 \\
\hline Missing & 41.6 & 46.6 & 30.8 & 4.7 & 29.2 & 11.1 & 264.0 & 11.0 & 48.1 & 55.5 \\
\hline Total & 46.8 & 48.5 & 30.6 & 4.8 & 29.5 & 10.8 & 264.1 & 10.9 & 44.4 & 54.0 \\
\hline
\end{tabular}

is 0.023 , which implies that controlling only for Age and Age squared brings about a limited improvement of prediction of the number of sick days. In models 2 and 3, the values of Cragg and Uhler's R2 have increased to 0.179 and 0.290 , which suggest that the prediction of sick days is substantially improved after controlling for the confounders, and further improved by control for previous births and the interactions of age and previous births. By control for occupational class in model 4 , the value increases to 0.462 ; thus, prediction of sick days is considerably improved when occupational class is included in the model.

Figure 3 displays the various associations between age and number of sick days in the preceding regression models. As the graph for model 1 indicates, the youngest and oldest women have the highest numbers of sick days. Before control for any covariates, the numbers of sick days among pregnant women aged 20, 30 and 45 are 48.9, 46.8 and 48.1, respectively. After control for calendar year, working hours, leave and marital status, the corresponding numbers are 49.9, 46.9 and 46.2, as revealed in the second graph, model 2.

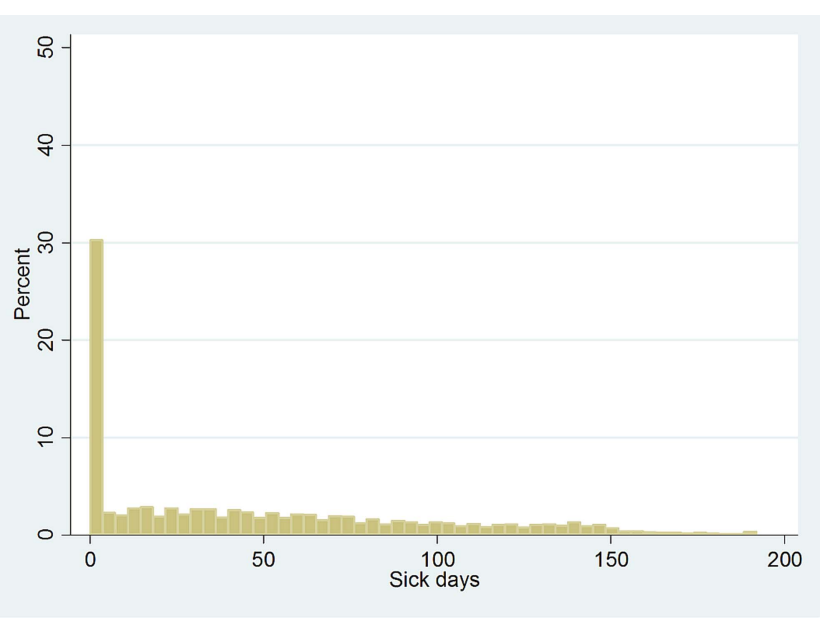

Figure 1 Distribution of days of sickness absence in the study population.
The interaction of previous deliveries and age is illustrated in the third graph, model 3. Young pregnant women with previous deliveries are characterised by a considerably higher number of sick days than equally aged women who are undergoing their first pregnancy. Pregnant women with previous births at the ages of 20, 30 and 45 have 60.3, 49.2 and 47.7 sick days, respectively. Among first-time pregnant women, the corresponding numbers are 49.1, 43.5 and 47.9.

Finally, the last graph shows that among pregnant women with previous births, the association between age and sick days is somewhat weakened after control for occupational class. However, 20-year-old women in this group still have 55.1 sick days, which is a substantially higher number than the 48.5 and 48.8 sick days which apply to the 30-year-olds and 45-year-olds. In contrast, control for class alters the association between age and sickness absence among women undergoing their first pregnancy. In this group, 30-year-olds still have the lowest number of sick days, 43.4, but 20-year-olds now have a value of 45.8 , which is considerably lower than the value of 48.7 , which applies to 45 -year-olds.

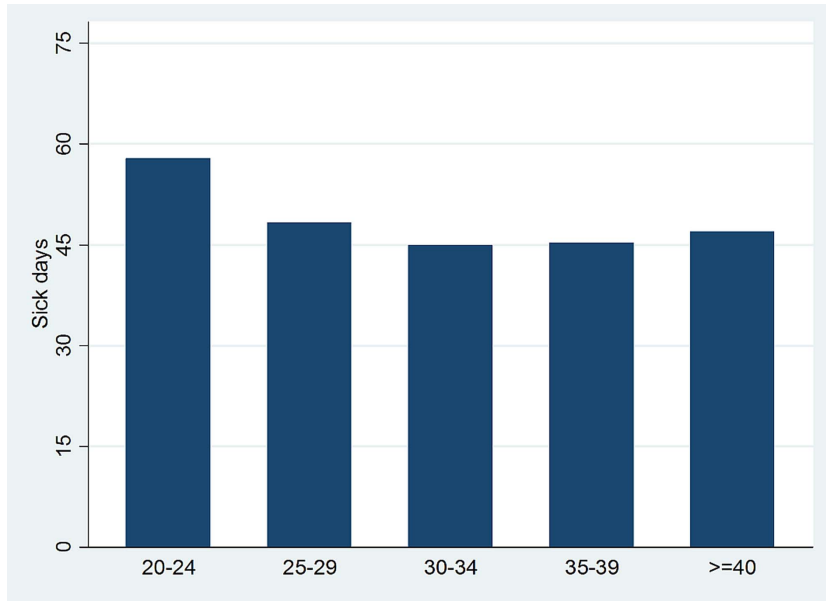

Figure 2 Days of sickness absence in different age groups. Only full-time employees included ( $\geq 37$ weekly working hours). 
Table 2 Zero-inflated Poisson regression with number of sick days as the dependent variable

\begin{tabular}{|c|c|c|c|c|}
\hline & Model 1 & Model 2 & Model 3 & Model 4 \\
\hline \multicolumn{5}{|l|}{ Count component } \\
\hline Age & -0.016 & -0.017 & -0.049 & -0.031 \\
\hline Age squared & 0.0002 & 0.0002 & 0.0007 & 0.0005 \\
\hline Previous deliveries & & & 0.374 & 0.330 \\
\hline Previous deliveries $\times$ age & & & -0.008 & -0.007 \\
\hline II Lower professionals & & & & 0.056 \\
\hline Illa Higher routine & & & & 0.185 \\
\hline Illb Lower routine & & & & 0.240 \\
\hline V Technicians & & & & 0.069 \\
\hline VI Skilled & & & & 0.212 \\
\hline VIla Semiskilled and unskilled & & & & 0.285 \\
\hline VIlb Agricultural & & & & 0.200 \\
\hline Missing & & & & 0.107 \\
\hline Constant & 4.448 & 3.350 & 3.749 & 3.231 \\
\hline \multicolumn{5}{|l|}{ Excess zero component } \\
\hline Constant & -1.341 & -1.341 & -1.341 & -1.341 \\
\hline Observations & 216541 & 216541 & 216541 & 216541 \\
\hline Cragg and Uhler's & 0.023 & 0.179 & 0.290 & 0.462 \\
\hline
\end{tabular}

\section{DISCUSSION}

The preceding analyses have shown that among pregnant women with previous births, young employees still have higher number of sick days after control for class, although the association between age and sick days is slightly weakened. However, among women undergoing their first pregnancy, young pregnant women no longer have the highest level of sick days after control for class. This indicates that the high number of sick days among young first-time pregnant women is due to a preponderance of working class women in this group, who are more prone to sickness absence. In younger age groups, women with previous deliveries have a higher number of sick days than do first-time pregnant women, but the difference decreases with age and levels out in the mid-40s. Regardless of previous pregnancies, pregnant women in their early 30s have the lowest number of sick days, and this pattern remains largely unchanged after control for class.

Using data from the Norwegian population registry eliminates risks of type I and II errors, thereby representing a strength of the study. Because the data are recorded by public entities, the empirical analyses do not suffer from non-response or self-reporting bias. Still, the registry has certain weaknesses. First, the registration of births first started in 1992, which implies that the few number of women who gave birth prior to this year and had their next delivery during the observation period are misclassified as women undergoing their first pregnancy. However, this weakness only applies to women who gave birth prior to 1992 and then had a birth interval of at least 12 years of duration, which is rare. Thus, any bias resulting from these misclassifications is limited. Second, only days of sickness absence covered by the
National Insurance are included in the registry. For employees who do not suffer from pregnancy-related conditions, this excludes the first 16 calendar days of the spell. Since 2002, employers can request reimbursement from National Insurance for expenditure on sickness absence among pregnant employees suffering periods of illness with a pregnancy-related diagnosis. In these cases, spells are registered from day 1 . This implies that the first 16 days are left censored for some spells, while other spells are complete. Although censoring may vary according to employer characteristics, such variation does not explain the high and increasing levels of sickness absence among young pregnant women, because this trend started before the amendment in 2002. ${ }^{16}$

The impact of excluding short-term sickness absence is also limited, because only $32 \%$ of Norwegian women's sickness absence is covered by the employer, ${ }^{48}$ and the figure is probably lower for pregnant employees, considering the separate rules of employer reimbursement which apply to absence spells caused by pregnancy-related diagnoses. High numbers of zeros often occur naturally in count data, which the variables of sickness absence are examples of. ${ }^{46}$ However, the censoring described above has contributed to heighten the numbers of zero in these variables even further. Zero-inflated Poisson regression was conducted to account for the excess zero in the distribution of sick days.

Controlling for occupational class implies a weakening of the negative association between age and sickness absence among women undergoing their first pregnancy and among those who have previously given birth. This indicates that the initial association between age and sickness absence during pregnancy is partly due to aspects of occupational class which these two groups 
Model 1

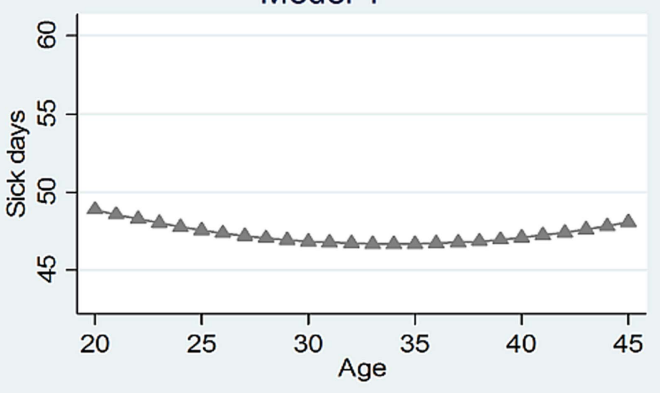

Model 3

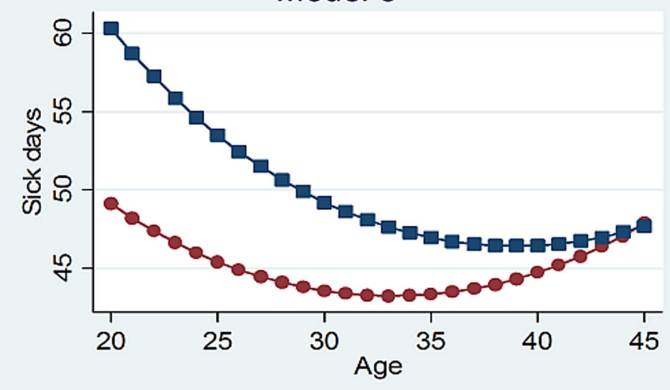

Model 2

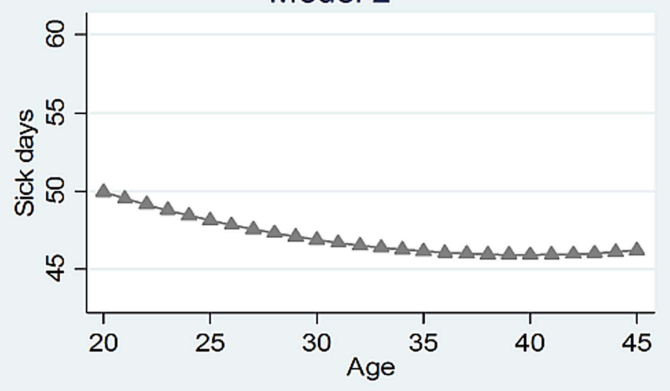

Model 4

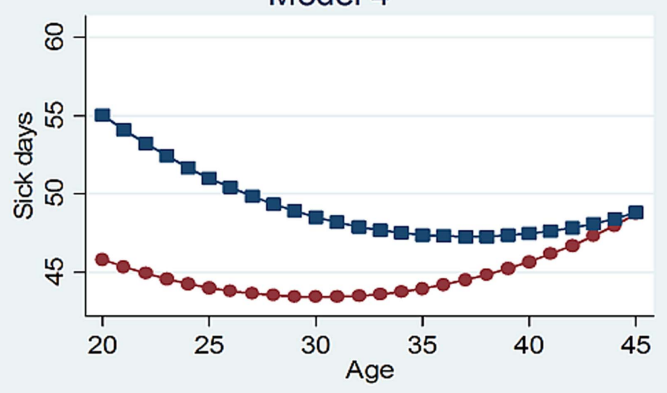

All pregnant women

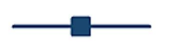

Previous birth(s)

First pregnancy

Figure 3 Marginal effect of age in models $1-4$ in the regression analysis.

have in common, such as physical and social working environment. However, occupational class only explains a small proportion of the heightened number of sick days among young pregnant women who have previously delivered. In this group, higher numbers of sick days apply to young pregnant women even after control for occupational class. Unfortunately, the data set does not allow for a more detailed analysis of this group, but previous research may hint at possible explanations.

Early transition to second or third births may reflect weaker employment orientation, especially since Norwegian women less frequently return to full-time employment after second or third births. ${ }^{49}$ Accordingly, the association between high number of sick days and early transition to second or third births that we find in our analyses may indicate that the threshold for sickness absence is lower for women whose future prospects are oriented towards family building rather than employment. However, the well-known association between homemaking and health problems implies that the apparent family orientation indicated by early transition to second or third births may reflect health problems rather than preferences. It is also worth noticing that early transition to second or third birth occurs much less frequently in Norway today than just a few decades ago. Sickness absence among women who undertake such transitions should thus be regarded in the light of the possible atypical situation of these women, because they may be affiliated with ethnic or religious groups that influence their sickness absence. Regardless of class and previous pregnancies, pregnant employees in their early 30 s are least prone to sickness absence. This may reflect a stronger work orientation in the group of women who postpone pregnancies to their $30 \mathrm{~s}$, as compared with younger mothers. Pregnant employees' 'Strategies of Secrecy, Silence and Supra-performance ${ }^{5}$ may shed light on this picture. In short, pregnant employees explain how they strive to adapt to workplace norms of occupational performance by delaying the announcement of their pregnancy, avoiding discussing it and compensating through increased flexibility and longer working hours, to demonstrate to their employer that the pregnancy does not make them less predictable or reliable as employees. Keeping sickness absence at an absolute minimum is also part of these strategies. Although these strategies seem quite hazardous, they also seem to reflect an important implicit assumption: the women do not want their pregnancy to jeopardise their occupational attachment. Women who postpone pregnancy to their early 30 s may be characterised by a general orientation towards future employment, which also influences their number of sick days during pregnancy. From the late 30s, the number of sick days during pregnancy increases with age, possibly due to the increased biological challenges.

It is also worth noticing that young women with previous deliveries are more prone to sickness absence than first-time pregnant women, although the difference 
between these groups decreases with age. In other words, childcare seems to inflate sickness absence more strongly among younger than among older pregnant women, which might indicate that early transition to motherhood is associated with rather traditional gender roles, while women who postpone pregnancy have partners who spend more time caring for children.

Future research on sickness absence should aim to investigate the relative importance of working conditions, social environment, motivation and health complaints for sickness absence during pregnancy. One should also investigate whether other risk factors for sickness absence apply to pregnant women, as compared with non-pregnant women and men. The causes and consequences of sickness absence among young pregnant women with previous deliveries may be of particular interest, as they are particularly prone to absence and possibly also future labour market exclusion.

\section{CONCLUSION}

Young pregnant women have a higher frequency of sickness absence than do their older counterparts. Contrary to expectations, the age differentials in sickness absence are stronger among pregnant women with previous deliveries than among those undergoing their first pregnancy. Occupational class largely accounts for the age differentials, but only among first-time pregnant women.

Acknowledgements The author would like to thank Magne Flemmen and Patrick Andersen, who most kindly provided a detailed manual for categorising Norwegian occupations in accordance with the class scheme of Erikson, Goldthorpe and Portocarero. The author also thanks Professor Hans-Tore Hansen for suggestions and feedback, Dr Øystein Ariansen Haaland for statistical advice, and Bo Vignes, Dr Miia Bask, Gisle Andersen, Professor Em Kari Wærness and Professor Arne Kalleberg for useful comments on the paper.

Funding This work was supported by The University of Bergen.

Competing interests None.

Ethics approval The Norwegian Data Protection Authority.

Provenance and peer review Not commissioned; externally peer reviewed.

Data sharing statement No additional data are available.

Open Access This is an Open Access article distributed in accordance with the Creative Commons Attribution Non Commercial (CC BY-NC 3.0) license, which permits others to distribute, remix, adapt, build upon this work noncommercially, and license their derivative works on different terms, provided the original work is properly cited and the use is non-commercial. See: http:// creativecommons.org/licenses/by-nc/3.0/

\section{REFERENCES}

1. Mills M, Rindfuss RR, McDonald P, et al. Why do people postpone parenthood? Reasons and social policy incentives. Hum Reprod Update 2011;17:848-60.

2. Duckitt K, Harrington D. Risk factors for pre-eclampsia at antenatal booking: systematic review of controlled studies. BMJ 2005;330:565-7.

3. Markussen S, Røgeberg O. Sykefravær rundt større livshendelser [Sickness absence due to life events]. Tidsskrift Den Nor Legeforen 2012;132:1231-4.

4. Rieck KME, Telle K. Sick leave before, during and after pregnancy. Acta Sociol 2013;56:117-37.
5. Gatrell C. Policy and the pregnant body at work: strategies of secrecy, silence and supra-performance. Gender Work Organ 2011;18:158-81.

6. Kristensen P, Nordhagen R, Wergeland E, et al. Job adjustment and absence from work in mid-pregnancy in the Norwegian Mother and Child Cohort Study (MoBa). Occup Environ Med 2008;65:560-6.

7. OECD. OECD economic surveys: Norway 2007. Norway: OECD Publishing, 2007.

8. Gatrell C. 'I'm a bad mum': pregnant presenteeism and poor health at work. Soc Sci Med 2011;72:478-85.

9. Edwards ME. Pregnancy discrimination litigation: legal erosion of capitalist ideology under Equal Employment Opportunity Law. Soc Forces 1996;75:247-68.

10. Major VS. Pregnancy in the workplace: stigmatization and work identity management among pregnant employees. University of Maryland, 2004.

11. Liff S, Ward K. Distorted views through the glass ceiling: the construction of women's understandings of promotion and senior management positions. Gender Work Organ 2001;8:19-36.

12. Acker J. Hierarchies, jobs, bodies: a theory of gendered organizations. Gender Soc 1990;4:139-58.

13. Gatrell C. Hard labour: the sociology of parenthood. McGraw-Hill International, 2004

14. Halpert JA, Wilson ML, Hickman JL. Pregnancy as a source of bias in performance appraisals. J Organ Behav 1993;14:649-63.

15. Gueutal HG, Luciano J, Michaels CA. Pregnancy in the workplace: does pregnancy affect performance appraisal ratings? J Bus Psychol 1995;10:155-67.

16. Ariansen AM, Mykletun A. Do increased gender differences in sickness absence follow from postponement of pregnancy? A register based descriptive analysis of all Norwegian full-time employees in 1993-2007. PLOS ONE 2014;9:e0093006.

17. Alexanderson K, Hensing G, Carstensen J, et al. Pregnancy-related sickness absence among employed women in a Swedish county Scand J Work Environ Health 1995;21:191-8.

18. Sydsjo A, Sydsjo G, Wijma B, et al. Changes in sick leave rates and the use of pregnancy-associated social benefits among pregnant Swedish women: an outcomes study. J Womens Health 1998:7:249-60.

19. Sydsjo A, Alexanderson K, Dastserri M, et al. Gender differences in sick leave related to back pain diagnoses-influence of pregnancy. Spine 2003;28:385-9.

20. Ron $\mathrm{L}$. The unfolding story of the second demographic transition. Popul Dev Rev 2010;36:211-51.

21. McLanahan S. Diverging destinies: how children are faring under the second demographic transition. Demography 2004;41:607-27.

22. Schmidt L, Sobotka T, Bentzen JG, et al. Demographic and medical consequences of the postponement of parenthood. Hum Reprod Update 2012;18:29-43.

23. Rønsen M. Fertility and public policies-evidence from Norway and Finland. Demogr Res 2004;10:143-70.

24. Mozurkewich EL, Luke B, Avni M, et al. Working conditions and adverse pregnancy outcome: a meta-analysis. Obstet Gynecol 2000;95:623-35.

25. Bonzini M, Coggon D, Palmer KT. Risk of prematurity, low birthweight and pre-eclampsia in relation to working hours and physical activities: a systematic review. Occup Environ Med 2007;64:228-43.

26. Lindbohm M. Physical workload-a risk factor for miscarriage? Scand J Work Environ Health 2013;39:321-3.

27. Jurewicz J, Hanke W, Makowiec-Dąbrowska T, et al. Exposure to pesticides and heavy work in greenhouses during pregnancy: does it effect birth weight? Int Arch Occup Environ Health 2005;78:418-26.

28. Burdorf A, Brand T, Jaddoe V, et al. The effects of work-related maternal risk factors on time to pregnancy, preterm birth and birth weight: the Generation R Study. Occup Environ Med 2011;68:197-204

29. Kaerlev L, Jacobsen LB, Olsen J, et al. Long-term sick leave and its risk factors during pregnancy among Danish hospital employees. Scand J Public Health 2004;32:111-17.

30. Strand K, Wergeland E, Bjerkedal T. Work load, job control and risk of leaving work by sickness certification before delivery, Norway 1989. Scand J Soc Med 1997;25:193-201.

31. Strand K, Wergeland E, Bjerkedal T. Job adjustment as a means to reduce sickness absence during pregnancy. Scand J Work Environ Health 1997;23:378-84

32. Warren S, Brewis J. Matter over mind? Examining the experience of pregnancy. Sociology 2004;38:219-36.

33. Johansson $\mathrm{G}$, Lundberg I. Components of the illness flexibility mode as explanations of socioeconomic differences in sickness absence. Int J Health Serv 2009;39:123-38. 
34. Virtanen P, Vahtera J, Nakari R, et al. Economy and job contract as contexts of sickness absence practices: revisiting locality and habitus. Soc Sci Med 2004;58:1219-29.

35. Ellingsaeter AL. Scandinavian welfare states and gender (de) segregation: recent trends and processes. Econ Ind Democracy 2013;0:1-18

36. Mastekaasa A. Sickness absence in female- and male-dominated occupations and workplaces. Soc Sci Med 2005;60:2261-72.

37. Duncan S, Irwin S. The social patterning of values and rationalities: mothers' choices in combining caring and employment. Soc Policy Soc 2004;3:391-9.

38. Annandale E, Hunt K. Gender inequalities in health. Berkshire: Open University Press Buckingham, 2000

39. Erikson R, Goldthorpe JH. The constant flux: a study of class mobility in industrial societies. Oxford University Press, USA, 1992.

40. Flemmen M, Andersen PL. Implementering av EGP klasseskjema for norske registerdata [Implementation of the class scheme of Erikson, Goldthorpe and Portocarero on Norwegian register data]. Oslo: Institutt for sosiologi og samfunnsgeografi, Universitetet i Oslo, 2009.

41. Krokstad S, Westin S. Health inequalities by socioeconomic status among men in the Nord-Trøndelag Health Study, Norway. Scand J Public Health 2002;30:113-24.
42. Cavelaars AE, Kunst AE, Geurts JJ, et al. Morbidity differences by occupational class among men in seven European countries: an application of the Erikson-Goldthorpe social class scheme. Int $J$ Epidemiol 1998:27:222-30.

43. Muntaner C, Borrell C, Vanroelen C, et al. Employment relations, social class and health: a review and analysis of conceptual and measurement alternatives. Soc Sci Med 2010;71:2130-40.

44. Bartley M, Carpenter L, Dunnell K, et al. Measuring inequalities in health: an analysis of mortality patterns using two social classifications. Soc Health IIIn 1996;18:455-75.

45. Lappegård T, Rønsen M. The multifaceted impact of education on entry into motherhood. Eur J Popul 2005;21:31-49.

46. Cameron AC, Trivedi PK. Microeconometrics using stata. Texas: Stata Press College Station, 2009.

47. Cragg JG, Uhler RS. The demand for automobiles. Can J Econ 1970;3:386-406.

48. Bjerkedal T, Thune O. Hva koster sykelønnsordningen [What are the costs of the sickness benefit]. Tidsskr Nor Legeforen 2003;123:662-3.

49. Rønsen M, Sundström M. Family policy and after-birth employment among new mothers-a comparison of Finland, Norway and Sweden. Eur J Popul 2002;18:121-52. 